\title{
Green and Sustainable Preparation of Flower Like ZnO Nanostructures via Soft Bio-template Approach for the Enhancement of Biomedical Applications
}

\section{N. Senthilkumar}

M.Kumarasamy College of Engineering

\section{E. Nandhakumar}

Vellore Institute of Technology

P. Priya

Periyar University

\section{Selvakumar}

Anna University

Vetha Potheher I ( $\sim$ potheher@aubit.edu.in )

Anna University Chennai - Regional Office Tiruchirappalli https://orcid.org/0000-0002-6721-1553

\section{Research Article}

Keywords: Bio-template, Flower like-ZnO Nanostructure, Anti-bacterial, Anti-cancer, Anti-arthritic activity

Posted Date: August 23rd, 2021

DOl: https://doi.org/10.21203/rs.3.rs-825393/v1

License: (9) This work is licensed under a Creative Commons Attribution 4.0 International License.

Read Full License

Version of Record: A version of this preprint was published at Applied Physics A on December 30th, 2021.

See the published version at https://doi.org/10.1007/s00339-021-05192-3. 


\section{Abstract}

Investigation onthe biomedical applications of flower like Zinc Oxide (ZnO) nanostructures (NSs)synthesized by using aqueous extract of Oryza punctata (red rice) is reported for the first time. For the sustainable preparation of ZnO NSs, the precursors zinc nitrate and the rice extract act as the biotemplate material. The powder X-ray diffraction analysis demonstrates the crystallographic structure and purity of the bio-prepared ZnO NSs. Fourier transform infrared spectral studies exhibits the existence of several functional groups in the rice extract and synthesized ZnO NSs. The FT-Raman spectroscopy analysis used to detect the presence of the defects in the synthesized material. The UV absorption onset shows the peaks at $270 \mathrm{~nm} \& 370 \mathrm{~nm}$ for rice extract and ZnO NSs, respectively. The optimal energy bandgap value for the ZnO NSs was found to be $3.29 \mathrm{eV}$. The zinc oxygen vacancies, zinc interstitial and surface defects were determined by photoluminescence spectroscopy. The dynamic light scattering analysis reveals the material stability and average particle size distribution of the prepared ZnO NSs. The flower like morphology of the ZnO NSs was confirmed by field emission scanning electron microscopy analysis. ZnO NSs were tested for cytotoxicity activity against MCF-7 cell line and antibacterial properties using two gram positive (Staphylococcus Aureus, Bacillus Subtilis) and two gram negative bacteria (Salmonella Paratyphi, Escherichia Coli). Significant antioxidant activity was studied by the bioprepared ZnO NSs against scavenging of DPPH (di(phenyl)-(2,4,6-trinitrophenyl)iminoazanium) free radicals. The flower like ZnO NSs showed a significant anti-arthritic activity which exhibited a maximum inhibition of protein denaturation $(78.94 \pm 1.62 \%)$ and membrane protective activity $(81.12 \pm 1.25 \%)$ at a dose of $0.5 \mathrm{mg} / \mathrm{mL}$ concentration.

\section{Introduction}

In recent trends, Nanomaterials (NMs) with size and structural dependent characteristics behavior are the essential for the various applications [1]. Especially, Zero-dimensional (0-D), One-dimensional (1-D), twodimensional (2-D) and three-dimensional (3-D) Nanostructures (NSs) have been developed for improve the performance of lithium ion batteries, fuel cells and supercapacitors by facile, novel and proficient synthesis and fabrication processes to control over size and morphology [1-6]. In addition, 0-D, 1-D, 2-D and 3-D NSs are exploiting unique characteristics in electric, optical and magnetic based applications depend upon their physical and chemical properties [6].Among them, 3-D semiconductor NSs like flower, tower, hollow microspheres, mesoporous single-crystal nanowires, dumbbell, nanotubes, nanodots, nanobridges, nanowalls, nanonails, nanohelixes, nut, seamless nanorings and polyhedral cages are much attention due to their potential use of electronic and photonic devices [7-15]. Researchers have been prepared and reported various 1-D and 3-D semiconductor $\mathrm{NSs}$ of $\mathrm{ZnO}, \mathrm{SnO}_{2}, \mathrm{TiO}_{2}, \mathrm{GaAs}, \mathrm{GaN}$ and $\mathrm{Si}$ based materials $[16,17]$. Among these, $\mathrm{ZnO}$ NSs have more attention owing to its wide bandgap (3.3eV), exciton binding energy $(60 \mathrm{meV})$ and designing of $n$-type semiconducting metal oxide devices using the multifunctional morphological, photonics and spintronic properties [18, 19]. Normally, ZnO NMs synthesized by various methods such as sol-gel, wet chemical, bio-template, hydrothermal, spray pyrolysis, electrochemical microwave-assisted method [20-22]. Among them, the bio-template method is 
relatively cheap, inexpensive, pollution-free and environmentally benign [22, 23]. As well as, bio-template is the biomorphic mineralization (or) natural material to prepare the micro and nano-scaled materials with morphologies, complexity, related unique functions and structures [24, 25]. So many studies have been investigated on the utilization of natural materials for the synthesis of $\mathrm{ZnO} N M$ s. For example, Cai et al. [26] reported DNA molecules are used to control the $\mathrm{ZnO}$ morphological structures by adjusting the $\mathrm{pH}$ values. Han et al. [27] have fabricated zinc oxide Nanoparticles (NPs) from natural silk material for photoluminescent property analysis. Nouroozi et al. [28] have developed brush-like ZnO nanorods via bio template of albumen (Egg white) in the sol-gel method. Ramimoghadam et al. [29, 22] have fabricated different morphologies like flake, rose, rod, flower and 3-D star like structures of $\mathrm{ZnO}$ by hydrothermal method, where palm olein and rice acts as a bio-template for synthesis of various ZnO NSs. Dong et al. [30] have reported egg-shell membrane acts as the bio-template for fabricating hierarchical ZnO fibrous through a solution soakage approach followed by a thermal treatment. Tomczak et al., [31] have prepared peptide assisted growth of flower-like $\mathrm{ZnO}$ structures. Hence, an effort has been made to synthesis flower like ZnO NSs using Oryza punctata (red rice) rice extract and succeeded. Because rice extract acts as a soft bio-template material which plays a crucial role for synthesize of various functional NMs [23]. Oryza punctata is one of the most troublesome weeds of cultivated rice in the southern United States [32]. The family and species of the Oryza punctataarePoaceae / Gramineae - grass family and Oryza punctata Kotzchy ex Steud.-Species [32]. The carbohydrate component is majorly present in Oryza punctata, which is most fascinating for agriculture bio resources that can be employed as non-metallic bioprecursor to develop the NMs [22]. Polymeric chains form in the carbohydrate component via glucose (starch) units, which are separated in linear amylase and amylopectin [33, 23]. These features are crucial structural factors in the development of novel functional NMs [33].Besides, Oryza punctata also contains bioactive compounds comprising phenolic antioxidants that have the capability of reducing the risk of diseases such as, coronary heart disease, preventing platelet aggregation, reducing the risk of cancer and inhibiting oxidative damage of lipids and low-density lipoproteins. Proanthocyanidins accumulation in rice bran gives the rice red pigment. Phytoconstituents such as peptides and phenolic compounds exhibit antioxidant and anticancer properties [34]. Ferulic acid and protocatechuic acid are the abundant phenolic compounds present in Oryzapunctata. Finocchiaro et al. [35] conveyed that proanthocyanidins of Oryzapunctata show potent antioxidant capacity.

Especially, biomedical applications are achieved by green synthesized ZnO NSs depend on their particle size, morphology, specific surface area and powder concentration, etc [36]. In this connection, ZnO NSs like a sponge, spherical, pyramid, hexagonal and rod shapes are fabricated from different leaves extracts of Cassia fistula, Tecomacastanifolia, Azadirachtaindica (L.), Cordiamyxa and Costuspictus for effective antibacterial activity [36-40]. Also, Balraj et al.,[41] synthesized spherical shaped $\mathrm{MgO}$ nanomaterial from Streptomyces $s p$. and used to test MCF-7 cancer cell with various concentrations. Lingaruju et al., [42] developed the ZnO NPs from Euphobiaheterophylla (L.) leaves and reported the potential anticancer activity against lung (A549) and hepatocarcinoma (HepG2) cells. Shobha et al., [43] reported the cytotoxicity effect using green synthesized ZnO NPs from Ricinuscommunis seeds onMDA-MB-231 cancer cells. Ngoepe et al., [44] prepared biogenic ZnO nanomaterial for lung cancer activity. Sukri et al., 
[45] reported that Punicagranatum fruit peels extract was utilized to synthesis the spherical and hexagonal shaped ZnO NSs, showed more effective on Colorectal cancer cell (HCT116) and normal colon cells (CCD112) activity than the fruit extracts. As well as, Rajkumar et al. has developed ZnO NPs using Andrographis paniculata leaves extract for anti-oxidants, anti-diabetic and anti-inflammatory activity to reduce the sugar level and to inflammations [46]. Agarwal et al. [47] have fabricated spherical like ZnO NPs via Kalanchoe pinnata leaf extract for excellent anti-inflammatory activity. Thatoi et al. [48] reported comparative studies on biomedical applications like antibacterial, antioxidant, antidiabetic and antiinflammatory activities. All the biological activities have been tested against green synthesized Ag-NPs and ZnO-NPs under photo-condition using the aqueous leaves extracts of Heritiera fomes and Sonneratia apetala. As a result, the goal of our research is to develop flower-like ZnO NSs using the bio-template approach in order to improve the biological applications.

\section{Materials And Methods}

\subsection{Materials}

The Oryzapunctatais found in Tamil Nadu, India's southernmost state. Merck India Ltd., provided all the chemicals required for the experiment. For the synthesis, Double Distilled (DD) water is employed as the solvent.

\subsection{Synthesis of flower like ZnO NSs using Oryzapunctata extract}

The Oryzapunctata rice was taken and weighed $20 \mathrm{gm}$. The rice was thoroughly washed with tap water for 2 to 3 times. After that, $100 \mathrm{ml}$ of DD water was added to the washed rice taken in the round bottom flask. Subsequently, the impurities were purified through Whatman No. 1 filter paper after being heated at $60^{\circ} \mathrm{C}$ for 1 hour. For the further step, the filtered extract was utilised as a capping and reducing agent.

In $50 \mathrm{ml}$ of DD water, $0.1 \mathrm{M}$ zinc acetate was dissolved and $5 \mathrm{ml}$ of red rice extract was added dropwise to the precursor solution while stirring constantly for 2 hours. The solution's colour changed from clear white to light red and a precipitate was formed. The resulting solution was centrifuged for 15 minutes at $16,000 \mathrm{rpm}$. Finally, the obtained product was dried in a hot air oven for 12 hours at $80^{\circ} \mathrm{C}$ and dried powders were employed for further characterization. Figure 1 shows a schematic representation of the synthesis of ZnO NSs.

\subsection{Growth mechanism of flower like ZnO NSs from the rice extract}

The carbohydrate component is majorly present in the red rice. The carbohydrate consists of polysaccharides which play multiple roles in the synthesis of oxide-based nanosized materials such as coating or capping, functionalizing, stabilizing, poring or coordinating agent [22]. Figure 2(a) shows the 
function of starch in the synthesis of $\mathrm{ZnO}$. Starch is a carbohydrate component made up of concentric rings in which amylase and amylopectin, both polymers of a-glucose units [23]. The polymeric structure of amylase consists of a linear and helical-shaped carbonaceous matrix, containing multiple polyols or hydroxyl groups, which form a protective layer that prevents agglomeration and acts as a shield for metal ions that perform a structure-directing role [49].The amylopectin chains expose an important number of hydroxyl groups, giving a strong hydrophilic character to starch granules and also involved both inter or intramolecular supramolecular association, which can coordinate transition metal ions and maintaining the NPs highly aggregated [49]. The small number of amylose molecules can form complexes with $\mathrm{Zn}^{2+}$ ions because of their high number of coordinating functional groups [50]. The majority of the $\mathrm{Zn}^{2+}$ ions may be closely associated with the starch molecules, so the initial crystal growth and nucleation might preferentially occur within the regions of both high starch and $\mathrm{Zn}^{2+}$ ions concentration leading to the formation of NPs [50]. They aggregate in the next step and by this process the small petals like structure will form. Then, the small petals like particles aggregate and form flower like ZnO NSs which is shown in Fig. 2(b). Where, the starch may act as a flocculant and forces aggregation. This effect becomes more important at higher polymer concentrations [25].

\subsection{Screening of antibacterial activity}

Totally four different bacterial strains (gram positive: Staphylococcus Aureus, Bacillus Subtilis and gram negative: Salmonella Paratyphi, Escherichia Coli) were obtained from Institute of Microbial Technology (MTCC), Chandigarh, India. All stock cultures were cultured in test tube of Muller-Hinton Broth (MHB) media and maintained at $37^{\circ} \mathrm{C}$ for $24 \mathrm{~h}$.

The antibacterial activity of flower like ZnO NSs against the selected bacterial strains was carried out by disc diffusion method. The agar plates were prepared and $0.1 \%$ of different inoculum (B. subtilis, E. coli,S. paratyphi and $S$. aureus) suspensions were uniformly swabbed on agar plates. Various concentration of flower like ZnO NSs (30, 40, 50 and $60 \mu \mathrm{l} / \mathrm{ml})$ were loaded on sterile disc $(6 \mathrm{~mm})$ and then the disks were loaded in surface of the culture plates. The disk loaded plates and control plates (without any disk) were incubated for $24 \mathrm{~h}$. Streptomycin was used as a positive control. At the end of the experiment, the zone of inhibition was analyzed in millimeter.

\subsection{Antioxidant activities}

\subsubsection{DPPH radical scavenging assay}

The antioxidant activity of flower like ZnO NSs was measured using a 2,2-diphenyl-1-picrylhydrazyl (DPPH) method. Briefly, $50 \mu \mathrm{l}$ of $\mathrm{ZnO} N S s(12.5-1000 \mu \mathrm{g} / \mathrm{mL})$ was added to the $100 \mu \mathrm{l}$ of DPPH solution in 96 well plates. The reaction mixture solution was mixed properly and kept for $1 \mathrm{~h}$ dark incubation. The colour reduction was determined by absorbance value $(517 \mathrm{~nm})$ using UV-Visible spectrophotometer. Ascorbic acid was employed as positive control to determine the resultant activity. The Radical Scavenging Activity (RSA) was determined by following equation: 
$\% \operatorname{RSA}=\left[\left(\mathrm{A}_{\mathrm{DPPH}}-\mathrm{A}_{S}\right) / \mathrm{A}_{\mathrm{DPPH}}\right] \times 100$

\subsection{In vitro cytotoxicity analysis}

The cytotoxicity effect of ZnO NSs was determined by MTT (3-[4,5-dimethylthiazol-2-yl]2,5diphenyltetrazolium bromide) based colorimetric assay against human MCF-7 cell lines (breast cancer cell line). The MCF-7 cancer cells were collected from National Centre for Cell Science (NCCS-Pune, INDIA, 411007). The cells were cultivated in Dulbecco's Eagle's Media with $10 \%$ of Fetal Bovine Serum (FBS) supplementation. The cells were maintained at room temperature $\left(37^{\circ} \mathrm{C}\right)$ with standard atmosphere $(5 \%$ of $\mathrm{CO}_{2}, 95 \%$ of aeration and $100 \%$ relative humidity) and the culture medium was changed two times per week.

The medium containing the selected concentrations of flower like ZnO NSs $(6.25,12.5,25,50$ and 100 $\mu \mathrm{g} / \mathrm{ml}$ )were added to the MCF-7 cells (96 well plates) and incubated at $37^{\circ} \mathrm{C}$ in a $\mathrm{CO}_{2}$ incubator. After $24 \mathrm{~h}$ incubation, $15 \mu \mathrm{l}$ of MTT dye solution ( $5 \mathrm{mg} / \mathrm{ml} \mathrm{MTT}$ in phosphate buffered saline) was added to the MCF7 cells (each well) and maintained at $37^{\circ} \mathrm{C}$. After $4 \mathrm{~h}$ incubation, $100 \mu \mathrm{l}$ of Dimethyl sulfoxide (DMSO)was added to the each well and the culture plates were read at $570 \mathrm{~nm}$. The $\%$ of cell inhibition was calculated and the cells were subjected to morphological analysis.

\subsection{In vitro antiarthritic activities \\ 2.7.1 Protein denaturation inhibition activity}

Bovine Serum Albumin (BSA) (5\% w/v of $2.4 \mathrm{~mL}$ aqueous solution) and various concentrations (100-500 $\mu \mathrm{g} / \mathrm{mL}$ ) of $\mathrm{ZnO}$ NSs were added in reaction container. The $\mathrm{pH}$ of the solutions were adjusted to 6.3 using $\mathrm{HCl}(1 \mathrm{~N})$ and incubated for 20 mins at $37^{\circ} \mathrm{C}$. After incubation, the sample solutions were maintained at

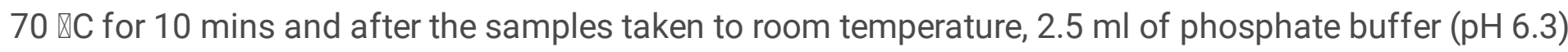
was added to each tube. The absorbance was measured using a spectrophotometer at $660 \mathrm{~nm}$.

Diclofenac was used as a reference standard [51]. The percentage of protein denaturation inhibition can be calculated by the following equation

$\%$ inhibition $=\frac{(\text { Abscontrol }- \text { Abssample })}{(\text { Abscontrol })} * 100$

\subsubsection{Membrane stabilization activity}

The membrane stabilization activity of ZnO NSs was analyzed by the Red Blood Cell Membrane Stabilization (RBCs-MS) assay protocol with few modifications [78]. Initially, healthy blood sample was collected and centrifuged for 10 mins (in $2500 \mathrm{rpm}$ ). The pellet was collected and washed twice with saline solution $(\mathrm{pH} 7.0)$. The final RBC cell suspension solution was prepared in normal saline solution (10\% v/v suspension). $2 \mathrm{~mL}$ of normal buffer saline, $1 \mathrm{~mL}$ of freshly prepared $10 \% \mathrm{v} / \mathrm{v}$ RBC suspension and $1 \mathrm{~mL}$ aqueous solution of $\mathrm{ZnO} N S s(100-500 \mu \mathrm{g} / \mathrm{mL})$ was added in reaction tubes. The assay mixture tubes were incubated at $57^{\circ} \mathrm{C}$ for $30 \mathrm{~min}$. After incubation, the mixtures were centrifuged at 2500 $\mathrm{rpm}$ and the supernatant solution was read using a spectrophotometer at $560 \mathrm{~nm}$. Diclofenac, an anti- 
inflammatory drug was used as a reference standard. The percentage of hemolysis was calculated by the following equation

$\%$ inhibition $=\frac{(\text { Abscontrol }- \text { Abssample })}{(\text { Abscontrol })} * 100$

\section{Results And Discussion}

\subsection{Powder X-ray Diffraction (PXRD)}

PXRD was recorded by the instrument Pro Penalty CAL with Cu-K radiation (1.5406) to determine the phase purity and crystalline quality of the prepared material. Figure 3 shows the PXRD pattern of ZnO NSs synthesized from the bio-template of Oryza punctata rice extract. In the PXRD pattern, all the diffraction angles of $31.75^{\circ}, 34.39^{\circ}, 47.50^{\circ}, 56.57^{\circ}, 62.75^{\circ}, 66.31^{\circ}, 67.92^{\circ}, 68.80^{\circ}$ and $76.83^{\circ}$ corresponds to (100), (002), (101), (102), (110), (103), (200), (112), (201) and (202) planes respectively for hexagonal wurtzite structure of $\mathrm{ZnO}$ and good agreement with the standard data JCPDS NO: 36-1451 [51]. The average crystalline size (D) was estimated by given Debye-Scherrer's formulae,

$D=0.94 \lambda / \beta \cos (\theta)$

Where ' $\beta$ ' denotes full-width half maximum of the peak and ' $\lambda$ ' represent the $X$-ray wavelength. The average crystalline size was found to be $25.98 \mathrm{~nm}$. The dislocation density ( $\delta$ ) (or) sample defects was evaluated from the average crystalline size using the given equation,

$\delta=1 /(D)^{2}$

The prepared material's dislocation density was found to be $14.8 \times 10^{-4}(\mathrm{~nm})^{-2}$. The strain was developed as a result of the crystal defect and distortion in the synthesized material. The Williamson-Hall $(\mathrm{W}-\mathrm{H})$ technique was used to compute the strain $(\varepsilon)$.

$\varepsilon=(\beta \cos (\theta)) /(4)$

According to Hooke's law, stress $(\sigma)$ can be determined from strain $(\varepsilon)$ and there is a linear proportionality relationship between stress $(\sigma)$ and strain $(\varepsilon)$ within the elastic limit.

$\sigma=\mathrm{C} \varepsilon$

Where, ' $C$ ' signifies bulk Young's modulus $\left(1.46 \pm 10^{10} \mathrm{~N} / \mathrm{m}^{2}\right)$. The strain $(\varepsilon)$ and stress $(\sigma)$ of the flower like ZnO NSs were found to be $0.00134 \%$ and $196 \mathrm{MPa}$, respectively [52-53]

\subsection{Fourier Transform Infrared Spectroscopy (FT-IR)}

The liquid samples were subjected to FT-IR analysis using a Perkin-Elmer spectrometer in the range of $400-4000 \mathrm{~cm}^{-1}$. The FTIR spectra of Oryza punctata rice extract and the synthesized ZnO NSs are 
shown in Fig. 4 (a \& b).From the Figure, the peaks at $3549 \mathrm{~cm}^{-1}$ and $3456 \mathrm{~cm}^{-1}$ reveal the $-\mathrm{OH}$ stretching vibration occurs in the Oryza punctata rice extract due to the presence of water $\left(\mathrm{H}_{2} \mathrm{O}\right)$, phenolic $\mathrm{OH}$, alcoholic $\mathrm{OH}$ or carboxylic $\mathrm{OH}$ groups $[22,51]$. The small peak at $2922 \mathrm{~cm}^{-1}$ corresponds to the stretching vibration of aliphatic $\mathrm{CH}$ groups in the rice extract [22].The peaks at $1575 \mathrm{~cm}^{-1}$ indicate the $\mathrm{C}=\mathrm{C}-$ stretching vibration, which may be due to amide and $\mathrm{OH}^{-}$of the carboxyl group of amino acid and proteins present in the extract [54].The peak at $1418 \mathrm{~cm}^{-1}$ may attributed to the angular deformation of the $\mathrm{C}-\mathrm{H}$ bending vibration in the starch molecule [22]. The band at $1018 \mathrm{~cm}^{-1}$ assigned to the stretching vibration of the $\mathrm{C}-\mathrm{O}-\mathrm{C}$ group in the hydro glucose ring of the starch molecule [22]. The small stretch at 414 $\mathrm{cm}^{-1}$ region denoted the bending vibration of $\mathrm{Zn}-0$ [55].

\subsection{FT-Raman Spectroscopy}

FT-Raman spectroscopy is used to examine the vibrational, stretching and rotational properties of the molecules present in the synthesized material. Figure 4(c) shows the FT-Raman spectrum of ZnO NSs obtained using a confocal Raman microscope (RENISHAW, United Kingdom) in the spectral range between 330 and $2000 \mathrm{~cm}^{-1}$. The prominent peaks at $408 \& 460 \mathrm{~cm}^{-1}$ areoriginating from the Raman active $\mathrm{E}_{2} \mathrm{H}$ mode of $\mathrm{ZnO}$ lattice [53]. The peaks arise at $340,362 \& 380 \mathrm{~cm}^{-1}$ isascribed due to zone boundary phonons modes of $3 \mathrm{E}_{2} \mathrm{H}-\mathrm{E}_{2} \mathrm{~L}$ [51]. The small (or) low-intensity peaks at $505 \mathrm{~cm}^{-1}$ indicates the $A_{1}$ (LO) mode. Normally, the $A_{1}$ (LO) mode is related to the structural defects (i.e.) oxygen vacancies, zinc interstitials, free carriers, etc., present in the $\mathrm{ZnO}$ lattice [51].

\subsection{UV-Visible Spectroscopy}

Figure 5 (a) \& 5 (b) shows the UV-Visible absorption spectra of Oryza punctata rice extract and synthesized ZnO NSs from the extract recorded by the UV-Visible (JASCO V650) spectrometer. From the Figure, the absorption wavelength peaks of $270 \mathrm{~nm}$ and $370 \mathrm{~nm}$ correspond to rice extract and synthesized ZnO NSs respectively. Furthermore, the $370 \mathrm{~nm}$ absorption peak demonstrates ZnO's intrinsic band-gap absorption, which is attributed to electron transfer from the valence to conduction band [22, 51]. Figure 5 (c)shows the Diffuse Reflectance Spectrum (DRS) of ZnO NSs. The optical band gap $\left(E_{g}\right)$ of ZnO NSs was determined using Kubelka-Munk method. In the Kubelka-Munk method, the reflectance values $(R)$ can be related to an absorption coefficient (a) through the relation given below,

$a=S / 2 v_{p} * F(R)$

Where $S$ denotes the scattering, $v_{p}$ denotes the volume fraction of the absorbing species and $F(R)$ denotes the Kubeleka-Munk function which is related to the diffuse reflectance given below.

$F(R)=(1-R)^{2} /(2 R)$

By neglecting the scattering coefficient (S), the Kubeleka-Munk function $F(R)$ can be directly proportional to the absorption coefficient (a) which is given below. 
So, the absorption coefficient (a) can be taken by 1. From the Tauc's equation for direct bandgap semiconductors (ahv) ${ }^{2} a\left(h v-E_{g}\right.$ ) by $F(R)$ to be rewritten as

$(F(R) h v)^{2} a\left(h v-E_{g}\right)$

The bandgap of ZnO NSs was found to be $3.29 \mathrm{eV}$ from the plot of $(F(R) h v)^{2}$ versus (hv). The obtained $\mathrm{ZnO}$ bandgap (3.29 eV) is less than the bulk $\mathrm{ZnO}(3.37 \mathrm{eV})$. So, the blue shift occurred in the synthesized sample owing to their quantum confinement effect [56]. Chemical impurities (or) vacancies existing in the intergranular regions generate the quantum confinement effect and it is creating new energy levels to reduce the bandgap energy $[56,57]$.

\subsection{Photoluniscence (PL) spectra analysis}

PL spectroscopy is utilized to investigate the effect of morphology on the optical, electronic and photochemical properties of semiconductor materials. The PL spectrum of ZnO NSs is shown in Fig. 5(d).UV peak near band edge (NBE) emission of the excitation wavelength appears at $334 \mathrm{~nm}$ and broad green emission (or) Deep Level visible Emission (DLE) appears at $545 \mathrm{~nm}$ [58]. The high exciton binding energy of $\mathrm{ZnO}(60 \mathrm{mV})$ promotes recombination of free excitons between the conduction and valance bands, which generates UV NBE emission $[59,60]$.The peak at $453 \mathrm{~nm}$ is ascribed to blue emission which creates due to zinc interstitial $\left(Z n_{i}\right)$ defect [59]. The broad DLE band (or) green emission (500-550 nm) is occurred owing to the recombination of a photogenerated hole with a singly ionized charge state of the specific structural defects such as zinc vacancies, oxygen vacancies $\left(V_{0}\right)$ and interstitial oxygen [62-65].

\subsection{Dynamic Light Scattering (DLS) analysis}

The stability of the synthesized NMs and the particle size (ranging from $5 \mathrm{~nm}$ to $5 \mu \mathrm{m}$ ) was analyzed by the DLS experiment in a liquid state using the instrument of Zeta sizer nano-series (Malvern). The pH of the dilute ZnO solution was measured as 6.9. Normally, biosynthesized NPs demonstrated the particles are monodispersed due to the polydispersity index value of 0.2 obtained from the colloidal solution [66]. From the Fig. 6 (a), the synthesized material's potential stability was around $-32.9 \mathrm{mV}$, which indicate the material's negative charge potential value may be attributable to the phytoconstituents (starch and carbohydrates) present in the rice extract and also confirms the presence of gross electro-static force with the synthesized ZnO NSs [51]. So, the ZnO NSs indicates potentially stable material. The particle size distribution of ZnO NSs is revealed in Fig. 6(b). From the particle size distribution, the size of the ZnO NSs was calculated as $224 \mathrm{~nm}$.

\subsection{Field Emission Scanning Electron Microscopy (FESEM)}

Figure 7(a-c)shows FESEM images of the uniform distribution of flower like ZnO NSs scanned by Carl Zeiss microscope Ltd, UK \& SIGMA instrument. The synthesized ZnO NSs are observed to be 
homogeneous, agglomerated and devoid of other dominant phases. Ramimoghadam et al., [22] and Amutha et al., [23] have reported on the structural formation of branched pattern using soft bio-templates and starch to demonstrate that the semi-crystalline granules are made from concentric rings (amylose and amylopectin) in which the basic components are aligned perpendicularly to the growth rings and the granule surface. In the flower like ZnO NSs, each pedal size was achieved around 100 to $200 \mathrm{~nm}$.

Figure 8(d) illustrates the EDAX spectrum of ZnO NSs, which exclusively indicates the presence of $\mathrm{Zn}$ and $O$ elements without any impurities. The corresponding weight and atomic percentage of zinc (Zn) and oxygen $(0)$ elements are given in the EDAX spectrum.

\subsection{Antibacterial activity}

Figure 8 (a-d) depicts the antimicrobial property of flower-like ZnO NSs, which was tested using zone inhibition methods on both gram positive (Staphylococcus aureus, Bacillus subtilis) and gram negative (Salmonella paratyphi, Escherichia coli) bacteria. Bacterial inhibition zones are in millimetre $(\mathrm{mm})$.By increasing the concentration of ZnO NSs, the growth rate of all the considered bacteria is reduced with the maximum inhibition of growth achieved at $60 \mathrm{~g} / \mathrm{ml}$. The highest inhibition zone was attained in Bacillus subtilis (28 mm) when compared to other bacterias such as Escherichia coli $(21 \mathrm{~mm})$, Salmonella paratyphi $(18 \mathrm{~mm})$ and staphylococcusaureus $(16 \mathrm{~mm})$. The Minimum Inhibitory Concentration (MIC) states that the minimum concentration of NPs required to impeded the growth of testing microorganisms. According to the statement, Salmonella paratyphi $(10 \mathrm{~mm})$ had a higher MIC value in $30 \mathrm{~g} / \mathrm{ml}$ than Staphylococcus aureus $(9 \mathrm{~mm})$, Escherichia coli $(8 \mathrm{~mm})$ and Bacillus subtilis (7 $\mathrm{mm})$, as presented in Table 1.The antibacterial properties of flower like ZnO NSs depends on many factors including size of the particles, morphology, specific surface area, powder concentration, etc. Zhang et al., stated that the ZnO NPs damages to the membrane wall of E. coli[69]. Such damages may be partly owing to direct communications between ZnO NSs and outer lipid layer of bacterial membrane surface or due to the chemical communications between hydrogen peroxide $\left(\mathrm{H}_{2} \mathrm{O}_{2}\right)$ and membrane proteins. The generated $\mathrm{H}_{2} \mathrm{O}_{2}$ penetrates the cell membrane and kills the bacteria by extrusion of the cytoplasmic contents thereby resulting in the death of the bacterium[70].Moreover, the antibacterial activity of the metal oxide NPs mostly emerged on the surface bind with the thiol (-SH) groups of protein present in the cell wall. This interface is responsible for cell lyses due to decreased cell permeability. Reason for the increase in the antibacterial activity with increasing concentration of ZnO NSs is presumed due to the increase of $\mathrm{H}_{2} \mathrm{O}_{2}$ concentration from the surface of $\mathrm{ZnO}$ NSs. Gunalan et al., proved that the green synthesized ZnO NPs show stronger antibacterial inhibition efficiency compared to chemically synthesized ZnO NPs [71]. 
Table 1

ZnO NSs fabricated from Oryza Punctataextract for antimicrobial activity against Grampositive and Gram-negative bacteria.

\begin{tabular}{|c|c|c|c|c|c|c|}
\hline \multirow[t]{2}{*}{ S. No } & \multirow[t]{2}{*}{ Micro Organisms } & \multicolumn{5}{|c|}{$\begin{array}{l}\text { Zone of inhibition (diameter in } \mathrm{mm} \text { ) at } \\
\text { various concentrations }\end{array}$} \\
\hline & & Control & $\begin{array}{l}30 \\
\mu l / n\end{array}$ & $40 \mu \mathrm{l} / \mathrm{ml}$ & $\begin{array}{l}50 \\
\mu l / n\end{array}$ & $60 \mu \mathrm{l} / \mathrm{ml}$ \\
\hline 1 & ${ }^{a}$ Escherichia coli & 18 & 8 & 12 & 16 & 21 \\
\hline 2 & a Salmonellaparatyphi & 16 & 10 & 11 & 14 & 18 \\
\hline 3 & ${ }^{b}$ Staphylococcusaureus & 18 & 9 & 13 & 14 & 16 \\
\hline 4 & ${ }^{b}$ Bacillussubtilis & 19 & 7 & 16 & 19 & 28 \\
\hline \multicolumn{7}{|c|}{ Control Streptomycin } \\
\hline \multicolumn{7}{|c|}{ a Gram -ve bacteria } \\
\hline${ }^{{ }^{b}}$ Gram & e bacteria & & & & & \\
\hline
\end{tabular}

\subsection{Antioxidant activity}

In the standard metabolic process, levels of antioxidants and free radicals are equalized. The overproduction of free radicals results in oxidative damage, leading to a variety of chronic diseases, such as diabetes, cancer and inflammation. In the biological system, antioxidant plays a significant part in scavenging toxic free radicals and supports in preventing damage of tissues and cells including DNA, proteins and lipids caused by free radicals. Natural antioxidants are in high demand due to their potential for disease prevention and health control[72]. The antioxidant activities of green synthesized ZnO NSs are assessed using DPPH, which is a simple and fast approach. The colour of DPPH turns from purple to yellow and gets converted into 1,1-diphenyl-2-picrylhydrazine with a decrease in absorbance at $517 \mathrm{~nm}$ after reduction by ZnO NS's indicates the scavenging potentials of the NPs. The slow color change of DPPH solution from purple to pale yellow in the presence of ZnO NSs is due to shifting of electron density present at oxygen atom to the odd electron present at nitrogen atom in DPPH [73]. Antioxidant activity of flower like ZnO NSs was found (Figure.9) to increase with the increase in concentration in a dosedependent manner from $12.5 \mu \mathrm{g} / \mathrm{mlto} 1000 \mu \mathrm{g} / \mathrm{ml}$. IC $\mathrm{IC}_{50}$ of ZnO NSs is $50.22 \mu \mathrm{g} / \mathrm{ml}$ and the $\mathrm{IC}_{50}$ value of standard ascorbic acid is $42.18 \mu \mathrm{g} / \mathrm{ml}$. Oryza punctata rice is known to consist of a significant amount of phenolic acids and proanthocyanidins, both reveal valuable biological activities incorporated with good antioxidant activity [74]. Proanthocyanidins belong to condensed tannins and are polymers and oligomers of flavan-3-ols. It shows good antioxidant and free radical scavenging activity because of the presence of various phenolic hydroxyl especially an ortho-dihydroxyl group. The phenolic ring confers antioxidant property by stabilizing and delocalizing unpaired electrons $[75,76]$. 


\subsection{Invitro cytotoxicity}

The evaluation of cytotoxicity is an essential part of toxicology assessment because it explains the cellular response to a toxicant. Figure 10(d) depicts the variation in cell activity of MCF-7 cells exposed to $6.25,12.5,25,50$ and $100 \mathrm{~g} / \mathrm{ml}$ concentrations by MTT assay. Figure revealed the gradual increase in percentage of cell inhibition ability by varying the concentration of ZnO NSs from6.25 to $100 \mu \mathrm{g} / \mathrm{mL}$. The concentration required to kill $50 \%$ of cells $\left(\mathrm{IC}_{50}\right)$ was $75.18 \mathrm{~g} / \mathrm{ml}$. The results demonstrate that, reduction in size of the viable cells happened when increase the concentration of ZnO NSs synthesized from Oryza punctata rice extract. Microscopic images of the impact of ZnO NSs on cancer MCF-7 cell line shown in Fig. 10 (b \& c) confirms the decrease in number of viable cells compared to that of the control (Fig. 10 (a)). The reduction in no of cells may be due to the Reactive Oxygen Species (ROS) generation exceeds the anti-oxidative defensive capability of the cell and hence decrease in cell viability occurs due to oxidative damage of the cell components. Gunaratneet al., observed to copherols and tocotrienols in rice bran exhibits anticancer activity [77]. Premanathan et al., reported the basic mechanism for cytotoxicity of $\mathrm{ZnO}$ NSs towards cancer cells might be by stimulating the production of ROS, which are responsible for the induction of apoptosis [78].

\subsection{Antiarthritic activity of ZnO NSs}

Denaturation of proteins is one of the characteristics that influence joint damage in rheumatoid arthritis and consequently promote the overproduction of autoantigens. Production of autoantigen/antibodies is associated with type-III hypersensitivity reaction, which is particularly related to arthritis, glomerulonephritis and erythematosus. The alteration of covalent, electrostatic, hydrophobic and cleavage of disulfide bonds are probably involved in the protein denaturation mechanism [80]. NonSteroidal Anti-Inflammatory Drugs (NSAIDs) like aspirin, diclofenac, ibuprofen and naproxen provide a protective effect against protein denaturation [79]. The present investigation on the inhibitory effect of ZnO NSs was evaluated against protein denaturation (serum albumin). The different dose of test samples $(0.1,0.2,0.3,0.4$ and $0.5 \mu \mathrm{g} / \mathrm{ml})$ provided significant protection against denaturation of protein. The increased absorbance of the test sample indicated the stabilization of protein and the values were compared with standard NSAID (Diclofenac sodium). The flower like ZnO NSs showed inhibitory activity of $78.94 \pm 1.62 \%$ at $0.5 \mathrm{mg} / \mathrm{mL}$ concentration and the standard diclofenac sodium exhibited inhibition of $88.56 \pm 1.41 \%$ at a concentration of $0.5 \mathrm{mg} / \mathrm{mL}$ (Fig. 11).

The RBC membrane is similar to the membrane of lysosome and the mechanism of stabilization of lysosomal membrane is an important in the inflammation pathway by preventing the release of activated neutrophil, bactericidal enzymes and proteases, which causes further tissue inflammation and damage. NSAIDs are commonly used to suppress the lysosomal enzyme release or stabilizing the lysosomal membrane [81]. In this study, the flower like ZnO NSs showed the significant RBC membrane protection when compared to standard diclofenac (NSAIDs). The ZnO NSs exhibited the $81.12 \pm 1.25 \%$ membrane stabilization at the $0.5 \mathrm{mg} / \mathrm{mL}$ concentration and diclofenac showed an inhibition of $89.24 \pm 0.94 \%$ at a concentration of $0.5 \mathrm{mg} / \mathrm{mL}$ (Fig. 12). 


\section{Conclusion}

Flower-like ZnO NSs were fabricated using bio template method for a wide range of biological activities. The synthesized material had a flower-like structure and was evenly distributed, as evidenced by the FESEM analysis. Excellent antimicrobial activity was achieved at higher concentrations of ZnO NSs due to production of ROS in the cell wall membrane that is more useful for raising antimicrobial activity against Staphylococcus aureus, Bacillus subtilis (gram-positive)and Salmonella paratyphi, Escherichia coli (gram-negative) bacteria. The flower-like ZnO NSs considerably scavenged the radicals in a dose-

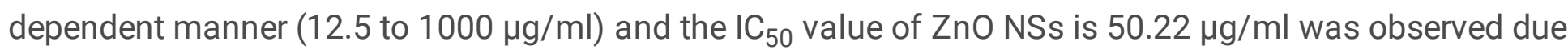
to free radicals. The percentage of cell inhibition increases with increasing concentration of ZnO NSs against MCF-7 breast cancer cell line. The green synthesized ZnO NSs showed significant inhibition of protein denaturation and membrane denaturation activity and that suggests to be used as an antiinflammatory as well as anti arthritic agent. Hence the present study concluded that the green synthesized flower-like ZnO NSs from Oryza punctata might be used for various biological and therapeutical applications.

\section{References}

1. A. Ananth, S. Dharaneedharan, M.S. Gandhi, M.S. Heo, Y.S. Mok, Novel RuO ${ }_{2}$ nanosheets - Facile synthesis, characterization and Application. Chem. Eng. J. 223, 729-736 (2013)

2. Y. Song, N. Wang, M.M. Fadlallah, S. Tao, Y. Yang, Z.L. Wang, Defect states contributed nanoscale contact electrification at ZnO nanowires packed film surfaces. Nano Energy 79, 105406 (2021)

3. A.G. Martínez, Y. Bai, G. Santana, R.S. Sprick, A. Dutt, Photocatalytic hydrogen production performance of 1-D ZnO nanostructures: Role of structural properties. Int. J. Hydrog. Energy 45, 31942-31951 (2020)

4. M.H. Huang, S. Mao, H. Feick, H.Q. Yan, Y.Y. Wu, H. Kind, E. Weber, R. Russo, P.D. Yang, Roomtemperature ultraviolet nanowire nanolasers. J. Science 292, 1897 (2001)

5. C. Lee, J.T.J. Lee, S.C. Lyu, Y. Zhang, H. Ruh, H.J. Lee, Field emission from well-aligned zinc oxide nanowires grown at low temperature. J. Appl. Phys. Lett. 81, 3648 (2002)

6. J.N. Tiwari, R.N. Tiwari, K.S. Kim, Zero-dimensional, one-dimensional, two-dimensional and threedimensional nanostructured materials for advanced electrochemical energy devices. Prog. Mater Sci. 57, 724-803 (2012)

7. M. Chennimalai, J.Y. Do, M. Kang, T.S. Senthil, A facile green approach of ZnO NRs synthesized via Ricinus communis L. leaf extract for Biological activities. Mater. Sci. Eng. C 103, 109844 (2019)

8. J.C. Tao, X. Chen, Y. Sun, Y. Shen, N. Dai, Controllable preparation of ZnO hollow microspheres by self-assembled block copolymer. J. Colloids Surf. A 330, 67-71 (2008)

9. Z. Wang, X.F. Qian, J. Yin, Z.K. Zhu, Large-scale fabrication of tower-like, flower-like and tube-like ZnO arrays by a simple chemical solution route. J. Langmuir 20, 3441-3448 (2004) 
10. J.H. Sun, S.Y. Dong, Y.K. Wang, S.P. Sun, Preparation and photocatalytic property of a novel dumbbell-shaped ZnO microcrystal photocatalyst. J. Hazard. Mater. 172, 1520-1526 (2009)

11. T.V.K. Karthik, V.R. Lugo, A.G. Hernandez, J.N. Jiménez, D.S. Campos, H.G. Pozos, D.M. .Anaya, E.C. Sáenz, Low temperature facile synthesis of ZnO nuts and needle like microstructures. Mater. Lett 246, 56-59 (2019)

12. J.P. Liu, X.T. Huang, Y.Y. Li, J.X. Duan, H.H. Ai, Large-scale synthesis of flower-like

13. ZnO structures by, a surfactant-free and low-temperature process. J. Mater. Chem. Phys. 98, 523527 (2006)

14. P.P. Ortega, C.C. Silva, M.A. Ramirez, G. Biasotto, C.R. Foschini, A.Z. Simoes, Multifunctional environmental applications of ZnO nanostructures synthesized by the microwave-assisted hydrothermal technique. Appl. Surf. Sci. 542, 148723 (2021)

15. Q. Li, D. Chen, J. Miao, S. Lin, Z. Yu, D. Cui, Z. Yang, X. Chen, Highly sensitive sensor based on ordered porous ZnO nanosheets for ethanol detecting application. Sensor Actuat B-Chem 326, 128952 (2021)

16. S. Pitchaiya, N. Eswaramoorthy, M. Natarajan, A. Santhanam, V.M. Ramakrishnan, V. Asokan, P. Palanichamy, B. Palanisamy, A. Kalimuthu, D.Velauthapillai, Interfacing green synthesized flake like$\mathrm{ZnO}$ with $\mathrm{TiO}_{2}$ for bilayer electron extraction in perovskite solar cells. New J. Chem 44, 8422-8433 (2020)

17. R.K. Joshi, J.J. Schneider, Assembly of one dimensional inorganic nanostructures into functional 2D and 3D architectures. J. Chem. Soc. Rev 41, 5285-5312 (2012)

18. S. Xu, Z.L. Wang, One-Dimensional ZnO Nanostructures: Solution Growth and Functional Properties. J. Nano Res 4, 1013-1098 (2011)

19. F.T. Thema, E. Manikandan, M.S. Dhlamini, M. Maaza, Green synthesis of ZnO nanoparticles via Agathosma betulina natural extract. Mater. Lett. 161, 124-127 (2015)

20. G. Sangeetha, S. Rajeshwari, R. Venckatesh, Green synthesis of zinc oxide nanoparticles by aloe barbadensis miller leaf extract: Structure and optical properties. J. Materials Research Bulletin 46, 2560-2566 (2011)

21. B.R. Krishnan, M. Ramesh, M. Selvakumar, S. Karthick, A. Sasikumar, D. Varun Geerthi, N. Senthilkumar, A facile green approach of cone-like ZnO NSs synthesized via Jatropha Gossypifolia leaves extract for photocatalytic and biological activity. J. Inorg. Organomet. Polym.and Mater 30, 4441-4451 (2020)

22. S. Tavakoli, M. Kharaziha, S. Nemati, Polydopamine coated ZnO rod-shaped nanoparticles with noticeable biocompatibility, hemostatic and antibacterial activity,Nano-Struct. Nano-Obj. 25, 100639 (2021)

23. D. Ramimoghadam, M.Z.B. Hussein, Y.H. Taufiq-Yap, Hydrothermal synthesis of zinc oxide nanoparticles using rice as soft biotemplate. Chem. Cent. J. 7, 136-146 (2013) 
24. C. Amutha, S. Thanikaikarasan, V. Ramadas, S.A. Bahadur, B. Natarajan, R. Kalyani, Synthesis, Characterization and Antibacterial Efficiency of ZnO Nanoparticles Using Rice as Soft Bio-Template. Optik 127(10), 4281-4286 (2016)

25. D. Yang, T. Fan, H. Zhou, J. Ding, D. Zhang, Biogenic hierarchical TiO2/SiO 2 derived from rice husk and enhanced photocatalytic properties for dye degradation. PLoS One 6, 24788 (2011)

26. H. Zhou, T. Fan, D. Zhang, Biotemplated Materials for Sustainable Energy and Environment: Current Status and Challenges. Chem. Sus. Chem 4, 1344-1387 (2011)

27. A.J. Cai, Y.L. Wang, S.T. Xing, L.Q. Du, Z.C. Ma, Tuned morphologies of DNA assisted ZnO struggling against Ph. J. Ceram. Int. 39, 605-609 (2013)

28. J. Han, H. Su, J. Xu, W. Song, Y. Gu, Y. Chen, W.J. Moon, D. Zhang, Silk mediated synthesis and modification of photoluminescent ZnO nanoparticles. J. Nanoparticle Res. 14, 726 (2012)

29. F. Nouroozi, F. Farzaneh, Synthesis and characterization of brush-like $\mathrm{ZnO}$ nanorods using albumen as biotemplate. J. Braz. Chem. Soc. 22, 484-488 (2011)

30. D. Ramimoghadam, M.Z.B. Hussein, Y.H.T. Yap, Synthesis and characterization of ZnO nanostructures using palm olein as biotemplate, Chem. Central J. 7, 71 (2013)

31. Q. Dong, H. Su, C. Zhang, D. Zhang, Q. Guo, F. Kiessling, Fabrication of hierarchical ZnO films with interwoven porous conformations by a bioinspired templating technique. Chem. Eng. J. 137, 428435 (2008)

32. M.M. Tomczak, M.K. Gupta, L.F. Drummy, S.M. Rozenzhak, R.R. Naik, Morphological control and assembly of zinc oxide using a biotemplate. J. Acta Biomater. 5, 876-882 (2009)

33. T.P. Carlson, E.P. Webster, M.E. Salassi, J.B. Hensley, D.C. Blouin, Imazethapyr plus Propanil Programs in Imidazolinone-Resistant Rice Weed. J. Weed Technology 25, 204-211 (2011)

34. J.M. Yan, X.B. Zhang, S. Han, H. Shioyama, Q. Xu, Synthesis of longtime water/air-stable Ni nanoparticles and their high catalytic activity for hydrolysis of ammonia - borane for hydrogen generation. Inorg. Chem. 48, 7389-7393 (2009)

35. W. Abeysekera, G. Premakumara, A. Dar, M.I. Choudhary, W. Ratnasooriya, M. Kashif, C. Mudassar, S. Ali, N. Chandrasekharan, J. Food Biochem. 39, 585-593 (2015)

36. F. Finocchiaro, B. Ferrari, A. Gianinetti, C. Dallasta, G. Galaverna, F. Scazzina, N. Pellegrini, Mol. Nutr. Food Res. 51, 1006-1019 (2007)

37. D. Suresh, P.C. Nethravathi, H. Udayabhanu, H. Rajanaika, S.C. Nagabhushana, Sharma, Green synthesis of multifunctional znic oxide ( $\mathrm{ZnO}$ ) nanoparticles using Cassia fistula plant extract and their photodegrative, antioxidant and antibacterial activities. Mater. Sci. Semicond. Process. 31, 446456 (2015)

38. S. Umavathi, S. Mahboob, M. Govindarajan, K.A.A. Ghanim, Z. Ahmed, P. Virik, N.A. Mulhm, M. Subash, K. Gopinath, C. Kavitha, Green synthesis of ZnO nanoparticles for antimicrobial and vegetative growth applications: A novel approach for advancing efficient high quality health care to human wellbeing. Saudi. J. Biol. Sci. 28, 1808-1815 (2021) 
39. S. Saif, A. Tahir, T. Asim, Y. Chen, M. Khan, S.F. Adil, Green synthesis of ZnO hierarchical microstructures by Cordiamyxa and their antibacterial activity,Saudi. J. Biol. Sci. 7, 1364-1371 (2019)

40. G. Sharmila, M. Thirumarimurugan, C. Muthukumaran, Green synthesis of ZnO nanoparticles using Tecomacastanifolia leaf extract: Characterization and evaluation of its antioxidant, bactericidal and anticancer activates. Microchem. J. 145, 578-587 (2019)

41. J. Suresh, G. Pradheesh, V. Alexramani, M. Sundrarajan, S.I. Hong, Green synthesis and characterization of zinc oxide nanoparticles using insulin plant (Costuspictus D. Don) and investigation of its antimicrobial as well as anticancer activities. Advanced in Natural Sciences: Nanoscience and Nanotechnology 9, 015008 (2018)

42. B. Balraj, N. Senthilkumar, I. Vetha Potheher, M. Arumozhi, Characterization, antibacterial, antiarthritic and in-vitro cytotoxic potentials of biosynthesized Magnesium oxide nanomaterial. Material Science \& Engineering B 231, 121-127 (2018)

43. K. Lingaraju, H. Raja Naika, H. Nagabhushana, G. Nagaraju, Euphobiaheterophylla (L.) mediated fabrication of ZnO NPs: Characterization and evaluation of antibacterial and anticancer properties, Biocatalysis and Agricultural Biotechnology, 18 (2019) 100894

44. N. Shobha, N. Nanda, A. ShivannaGiresha, P. Manjappa, P. Sophiya, K.K. Dharmappa, B.M. Nagabhushana, Synthesis and characterization of Zinc oxide nanoparticles utilizing seed source of Ricinus communis and study of its antioxidant, antifungal and anticancer activity. Materials Science and Engineering: C 97, 842-850 (2019)

45. N.M. Ngoepe, Z. Mbita, M. Mathipa, N. Mketo, B. Ntsendwana, N.C. Hintsho-Mbita, Biogenic synthesis of ZnO nanoparticles using Monsoniaburkeana for use in photocatalytic, antibacterial and anticancer applications. Ceram. Int. 44, 16999-17006 (2018)

46. S.N. Sukri, K. Shameli, M.M. Wong, S.Y. Teow, J. Chew, N.A. Ismail, Cytotoxicity and antibacterial activities of plant-mediated synthesized zinc oxide ( $\mathrm{ZnO})$ nanoparticles using Punicagranatum (pomegranate) fruit peels extract. J. Mol. Struct. 1189, 57-65 (2019)

47. G. Rajakumar, M. Thiruvengadam, G. Mydhili, T. Gomathi, I.M. Chung, Green approach for synthesis of zinc oxide nanoparticles from Andrographis paniculata leaf extract and evaluation of their antioxidant, anti-diabetic, and anti-inflammatory activities. Bioprocess. Biosyst. Eng. 41, 21-30 (2018)

48. H. Agarwal, V.K. Shanmugam, Synthesis and optimization of zinc oxide nanoparticles using Kalanchoe pinnata towards the evaluation of its anti-inflammatory activity. Journal of Drug Delivery Science and Technology 54, 101291 (2019)

49. P. Thatoi, R.G. Kerry, S. Gouda, G. Das, K. Pramanik, H. Thatoi, J.K. Patra, Photomediated green synthesis of silver and zinc oxide nanoparticles using aqueous extracts of two mangrove plant species, Heritiera fomes and Sonneratia apetala and investigation of their biomedical applications. J. Photochem. Photobiol. B Biol. 163, 311-318 (2016) 
50. D. Visinescu, A. Tirsoaga, G. Patrinoiu, M. Tudose, C. Paraschiv, A. lanculescu, O. Carp, Green Synthetic Strategies of Oxide Materials: Polysaccharides-Assisted Synthesis. Rev. Roum. Chim 55, 1017-1026 (2010)

51. A. Taubert, G. Wegner, Formation of uniform and monodisperse zincite crystals in the presence of soluble starch. J. Mater. Chem. 12, 805-807 (2002)

52. N. Senthilkumar, E. Nandhakumar, P. Priya, D. Soni, M. Vimalan, I. Vetha Potheher, Synthesis of ZnO nanoparticles using leaf extract of Tectonagrandis (L.) and their anti-bacterial, anti-arthritic, antioxidant and in vitro cytotoxicity activities (2017). New J. Chem. 41, 10347-10356 (2017)

53. P. Bindu, S. Thomas, Estimation of lattice strain in ZnO nanoparticles: X-ray peak profile analysis. J. Theor. Appl. Phys 8, 123-134 (2014)

54. K.V. Peruman, M. Mahendran, S. Seenithurai, R. Chokkalingam, R.K. Singh, V. Chandrasekaran, Internal stress dependent structural transition in ferromagnetic $\mathrm{Ni}-\mathrm{Mn}-\mathrm{Ga}$ nanoparticles prepared by ball milling. J. Phys. Chem. Solids 71, 1540-1544 (2010)

55. B. Balraj, N. Senthilkumar, C. Siva, R. Krithikadevi, A. Julie, I. Vetha Potheher, M. Arulmozhi, Synthesis and characterization of Zinc Oxide nanoparticles using marine Streptomyces sp. with its investigations on anticancer and antibacterial activity. Res.Chem. Intermed. 43, 2367-2376 (2017)

56. N. Senthil Kumar, M. Ganapathy, S. Sharmila, M. Shankar, M. Vimalan, I. Vetha Potheher, $\mathrm{ZnO} / \mathrm{Ni}(\mathrm{OH})_{2}$ core-shell nanoparticles: Synthesis, optical, electrical and photoacoustic property analysis. J. Alloy. Compd. 703, 624-632 (2017)

57. K. Ocakoglu, Sh.A. Mansour, S. Yildirimcan, A.A.A. Ghamdi, F.E. Tantawy, F. Yakuphanoglu, Microwave-assisted hydrothermal synthesis and characterization of $\mathrm{ZnO}$ nanorods. J. SpectrochimicaActa Part A 148, 362-368 (2015)

58. V. Vijayabala, N. Senthilkumar, K. Nehru, R. Karvembu, Hydrothermal synthesis and characterization of ruthenium oxide nanosheets using polymer additive for supercapacitor applications, J Mater Sci: Mater Electron, DOI: 10.1007/s10854-017-7919-x

59. H. Raj Pant, B. Pant, H.J. Kim, A. Amarjargal, C. Hee Park, L.D. Tijing, E. Kyo Kim, C. Sang, Kim, A green and facile one-pot synthesis of $\mathrm{Ag}-\mathrm{ZnO} / \mathrm{RGO}$ nanocomposite with effective photocatalytic activity for removal of organic pollutants. J. Ceram.Int 39, 5083-5091 (2013)

60. P. Rostami, A. Nemati, M.M. Byranvand, R. Mohammadpour, H. Faridi, One-pot synthesis of ZnO nanoparticles and submicron aggregates for dye-sensitized solar cells, J. Mater. Lett. (2015) 433436

61. N.K. Singh, S. Shrivastava, S. Rath, S. Annapoorni, Optical and room temperature sensing properties of highly oxygen deficient flower-like ZnO nanostructures. J. Appl. Surf. Sci. 257, 1544-1549 (2010)

62. P.K. Samanta, S.K. Patra, P. Roy, Chaudhuri, Violet emission from flower-like bundle of ZnOnanosheets. J. Physica E 41, 664-667 (2009)

63. J.H. Yang, J.H. Zheng, H.J. Zhai, L.L.Yang, Low temperature hydrothermal growth and optical properties of ZnO nanorods. J. Cryst.Res. Technol. 44, 87-91 (2009) 
64. N.Y. Garces, L. Wang, L. Bai, N.C. Giles, L.E. Halliburton, G. Cantwell, Role of copper in the green luminescence from ZnO crystals, J. Appl. Phys. Lett. (2002)

65. K. Elumalai, S. Velmurugan, S. Ravi, V. Kathiravan, G. Adaikala, Raj, Bio-approach: Plant mediated synthesis of ZnO nanoparticles and their catalytic reduction of methylene blue and antimicrobial activity, J. Advanced Powder Technology (2015)

66. H.R. Madan, S.C. Sharma, D. Udayabhanu, Y.S. Suresh, H. Vidya, H. Nagabhushana, K.S. Rajanaik, S.C. Anantharaju, P. Prashantha Sadananda Maiya, Facile Green Fabrication of Nanostructure ZnO Plates, Bullets, Flower, Prismatictip, Closed pine cone: Their Antibacterial, Antioxidant, Photoluminescent and Photocatalytic Properties, J. Spectrochimica Acta Part A: Molecular and Biomolecular Spectroscopy (2015)

67. B. Balraj, M. Arulmozhi, C. Siva, S. Abimanyu, R. Krithikadevi, R.M. Thaneswari, Cytotoxic potentials of biologically fabricated platinum nanoparticles from Streptomyces sp. on MCF-7 breast cancer cells. IET Nanobiotechnol 11, 241-246 (2016)

68. G. Zhang, X. Shen, Y. Yang, Facile synthesis of monodisperse porous ZnO spheres by a soluble starch-assisted method and their photocatalytic activity. J.Phys.Chem C 115(15), 7145-7152 (2011)

69. D. Raoufi, Synthesis and photoluminescence characterization of ZnO nanoparticles. Luminescence 134, 213-219 (2013)

70. L. Zhang, Y. Jiang, Y. Ding, M. Povey, D. York, Investigation into the antibacterial behaviour of suspensions of ZnO nanoparticles (ZnO nanofluids). J. Nanoparticle Res. 9, 479-489 (2006)

71. S. Sonia, H. Linda Jeeva Kumari, K. Ruckmani, M. Sivakumar, Antimicrobial and antioxidant potentials of biosynthesized colloidal zinc oxide nanoparticles for a fortified cold cream formulation: A potent nano cosmeceutical application. Mater. Sci. \& Eng. C 79, 581-589 (2017)

72. S. Gunalan, R. Sivaraj, V. Rajendran, Green synthesized ZnO nanoparticles against bacterial and fungal pathogens. Prog. Nat. Sci. 22,693-700 (2012)

73. M.R. Venkateswaran, S. Jayabal, S. Murugesan, S. Periyasamy, Identification of polyphenolic contents, in vitro evaluation of antioxidant and antidiabetic potentials of a polyherbal formulationMehani, Natural product research. 2019,1-5

74. D. Das, B.C. Nath, P. Phukon, A. Kalita, S.K. Dolui, Synthesis of ZnO nanoparticles and evaluation of antioxidant and cytotoxic activity. Colloids Surf., B 111, 556-560 (2013)

75. D. Suresh, P.C. Nethravathi, M.P. Udayabhanu, Kumar, H.R.Naika, H., Nagabhushana, S.C. Sharma, Chironji mediated facile green synthesis of ZnO nanoparticles and their photoluminescence, photodegradative, antimicrobial and antioxidant activities. Mater. Sci. Semiconduct. Process. 40, 759-765 (2015)

76. A. Gunaratne, K. Wu, D. Li, A. Bentota, H. Corke, Y.Z. Cai, Antioxidant activity and nutritional quality of traditional red-grained rice varieties containing proanthocyanidins. Food Chem 138, 1153-1161 (2013)

77. P. Goufo, H. Trindade, Rice antioxidants: phenolic acids, flavonoids, anthocyanins, proanthocyanidins, tocopherols, tocotrienols, y-oryzanol, and phytic acid. Food science \& nutrition 2 , 
75-104 (2014)

78. F. Namvar, H.S. Rahman, R. Mohamad, S. Azizi, P.M. Tahir, M.S.Chartrand,S.K. Yeap, Cytotoxic effects of biosynthesized zinc oxide nanoparticles on murine cell lines, Evidence-Based Complementary and Alternative Medicine. 2015, 1-11

79. M. Premanathan, K. Karthikeyan, K. Jeyasubramanian, G. Manivannan, Selective toxicity of ZnO nanoparticles toward Gram-positive bacteria and cancer cells by apoptosis through lipid peroxidation. Nanomed. Nanotechnol. Biol. Med. 7, 184-192 (2011)

80. S. Murugesan, M.R. Venkateswaran, S. Jayabal, S. Periyasamy, Evaluation of the antioxidant and anti-arthritic potential of ZingiberofficinaleRosc.by in vitro and in silico analysis. S. Afr. J. Bot. 130, 45-53 (2020)

81. I.L. Elisha, J.P. Dzoyem, L.J. McGaw, F.S. Botha, J.N. Eloff, The anti-arthritic, anti-inflammatory, antioxidant activity and relationships with total phenolics and total flavonoids of nine South African plants used traditionally to treat arthritis. BMC Complement. Altern. Med. 16, 307 (2016)

82. C.A. Anosike, O. Obidoa, L.U. Ezeanyika, Membrane stabilization as a mechanism of the antiinflammatory activity of methanol extract of garden egg (Solanumaethiopicum). DARU J. Pharm. Sci. 20, 76 (2012)

\section{Figures}

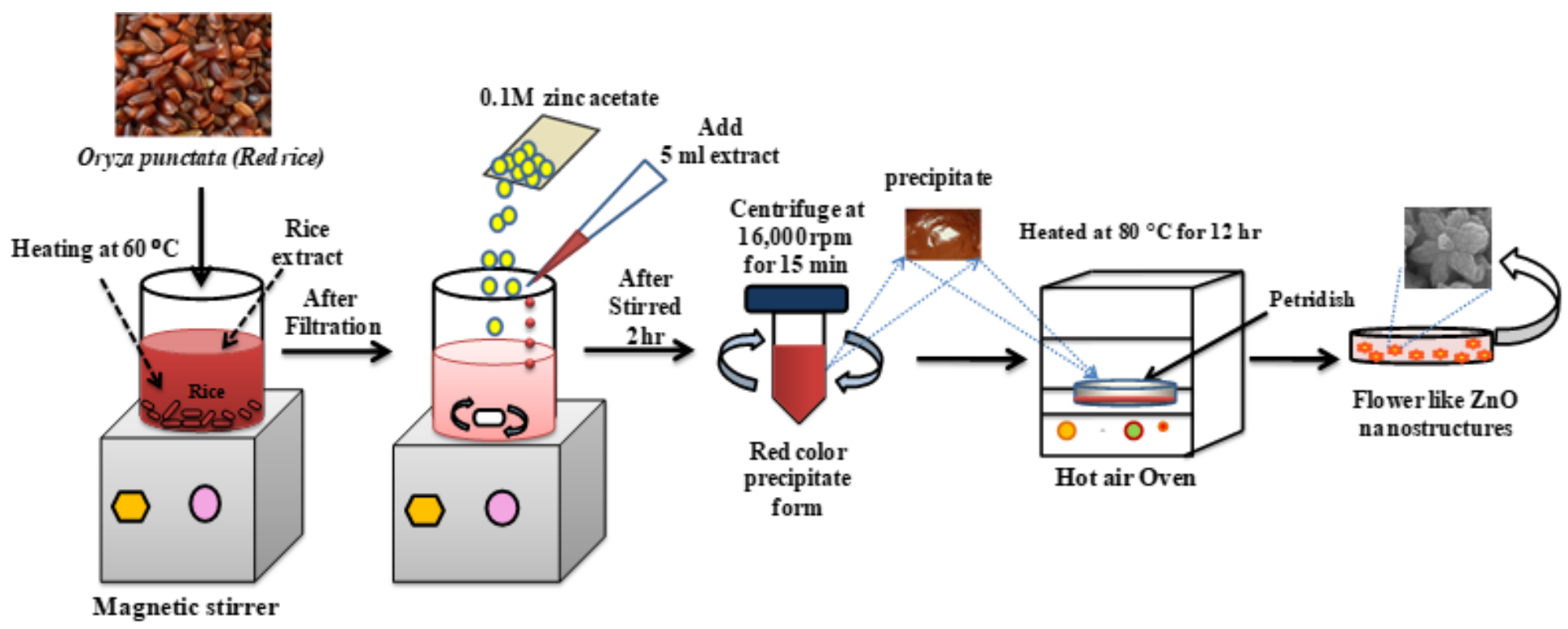

Figure 1

Schematic representation on the synthesis procedure of flower like ZnO NSs. 

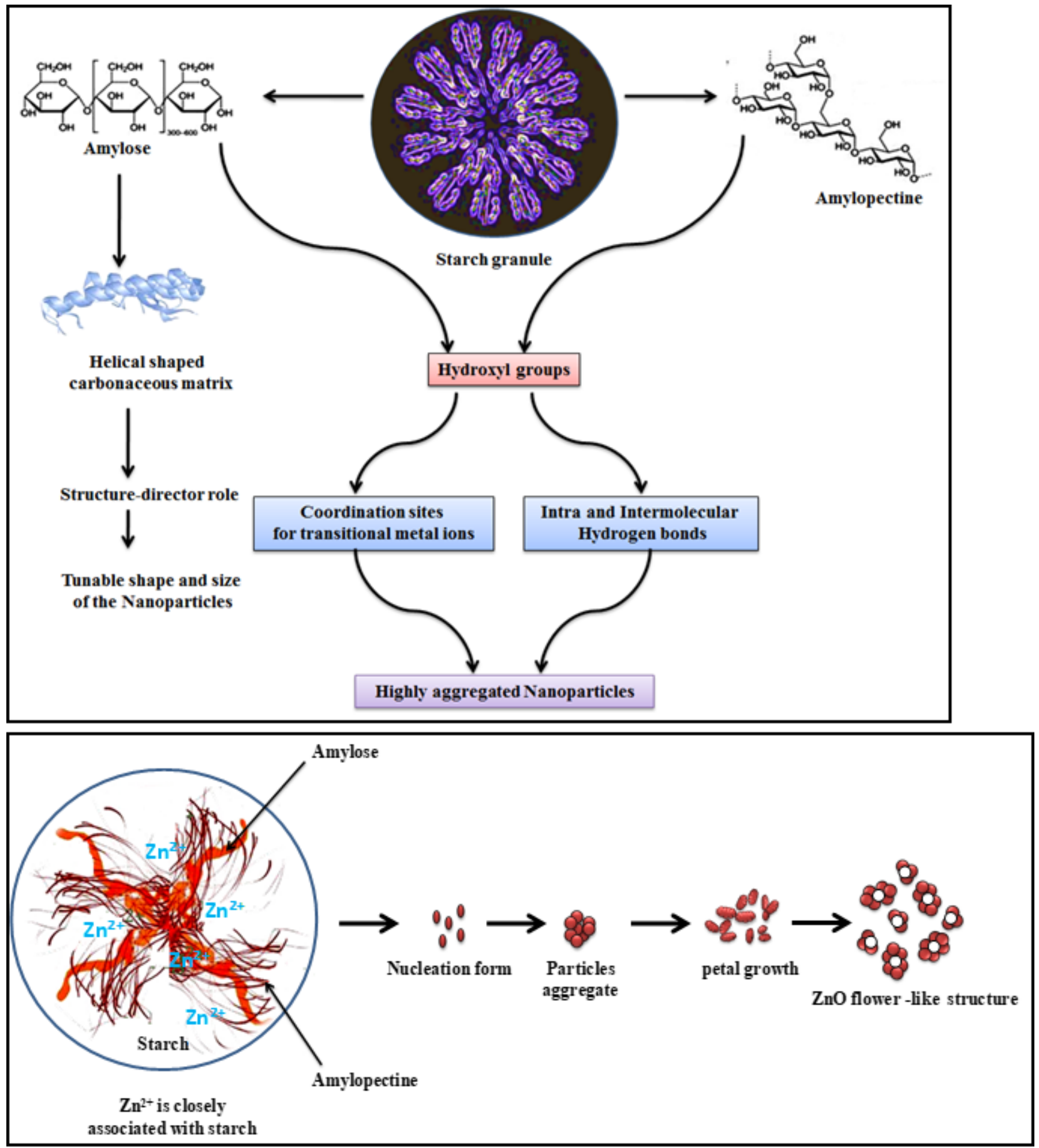

Figure 2

(a).The function of starch in the synthesis of ZnO NSs. (b).Schematic illustration on the formation mechanism of flower like ZnO NSs from the starch. 


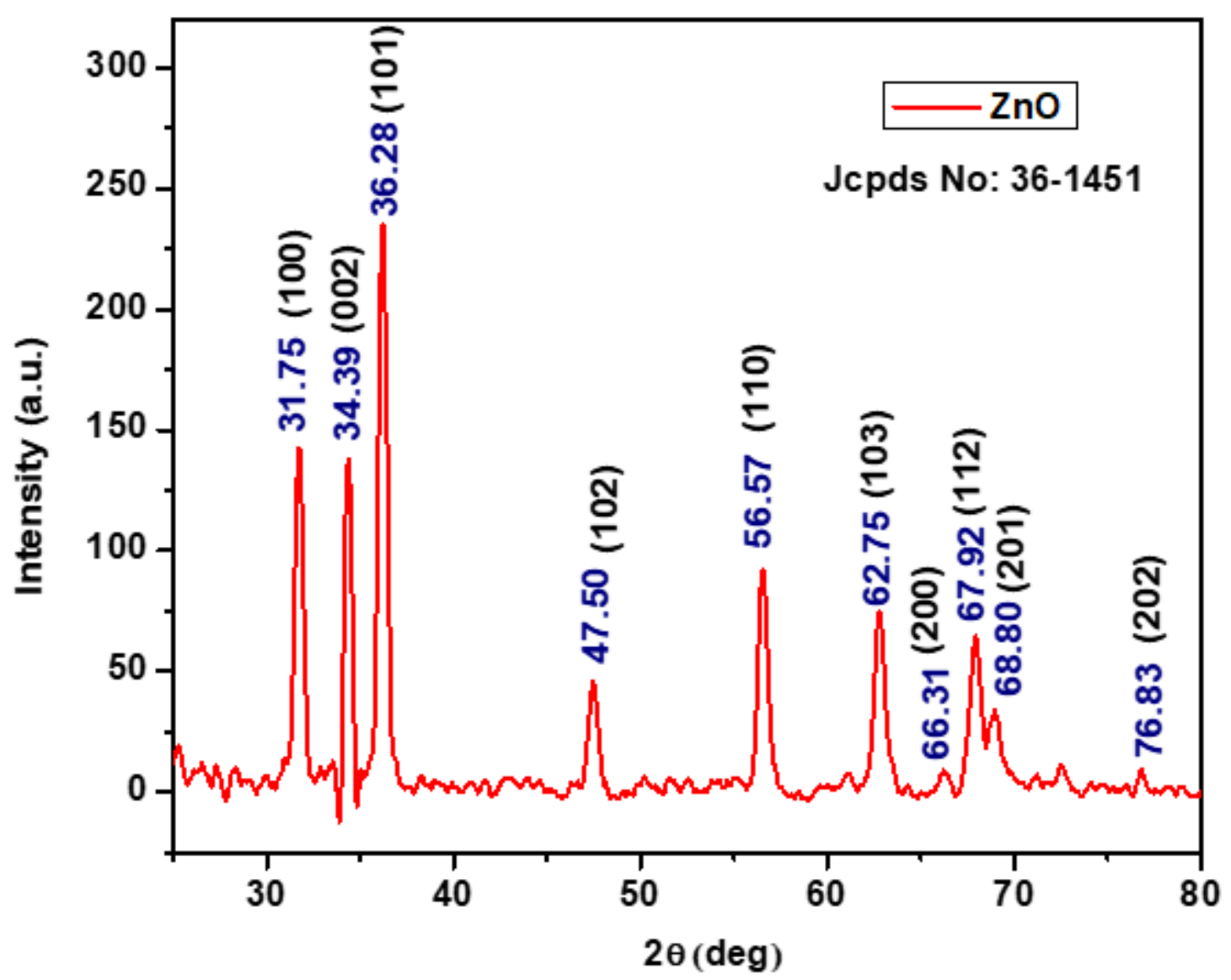

Figure 3

PXRD patternof the green synthesized ZnO NSs.
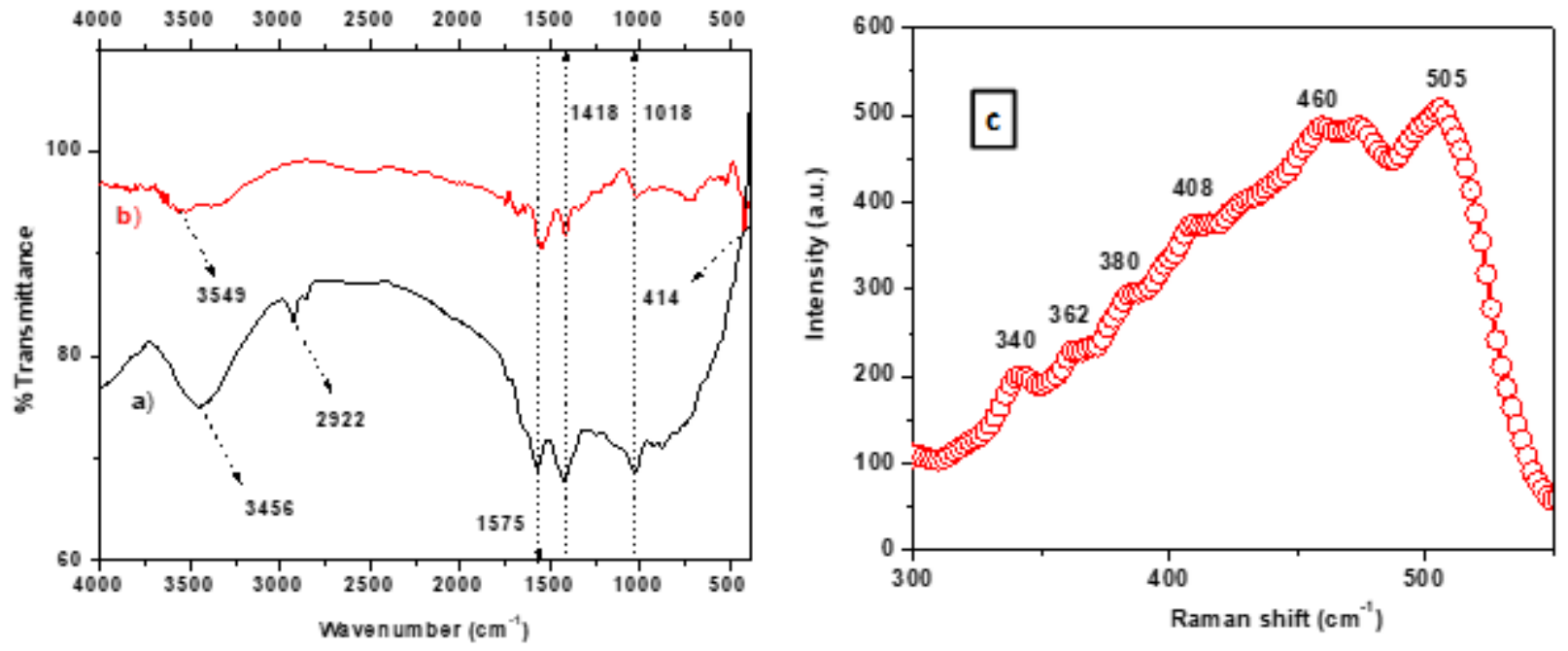

Figure 4

FTIR spectra of (a) Rice extract, (b) ZnO NSs and (c) Raman spectrum of ZnO NSs 

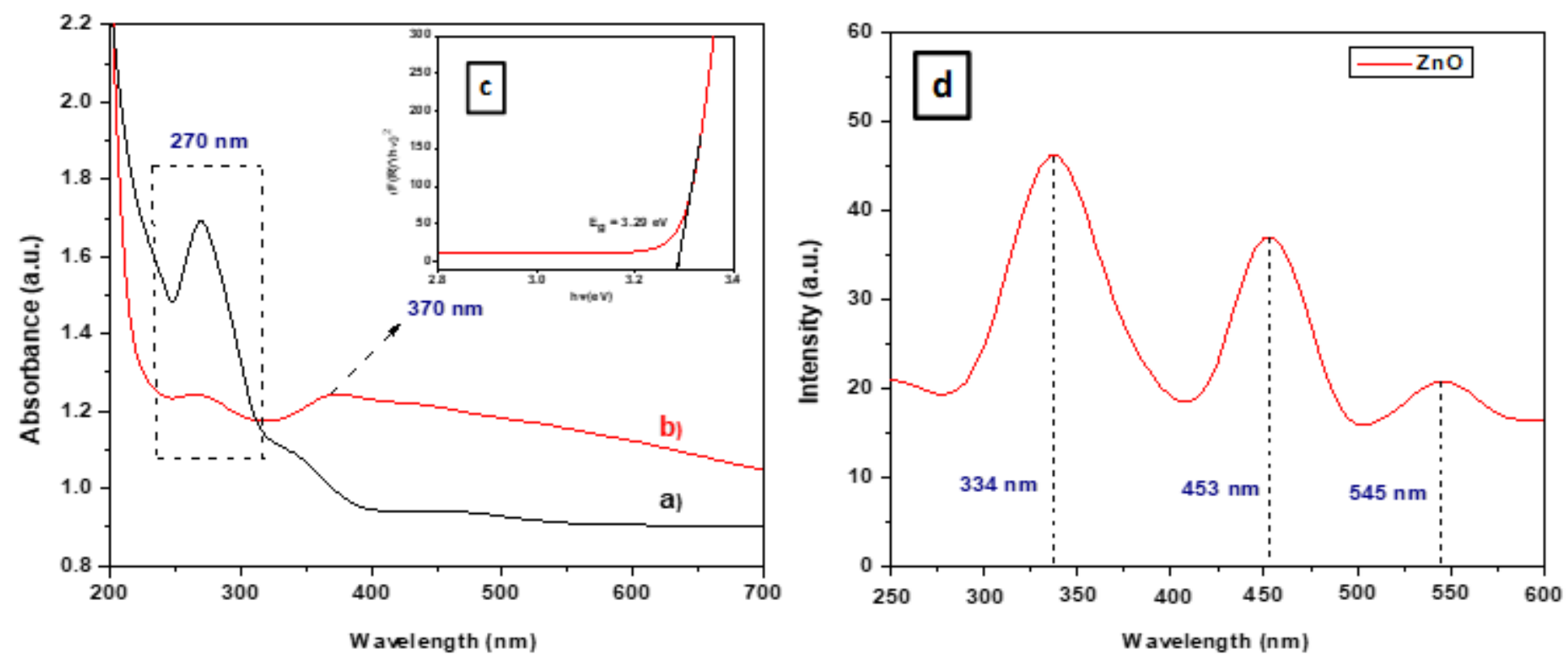

Figure 5

UV-Visible spectra of (a) rice extract, (b) ZnO NSs, (c) Tauc's plot of ZnO NSs and (d) PL spectrum of ZnO NSs.
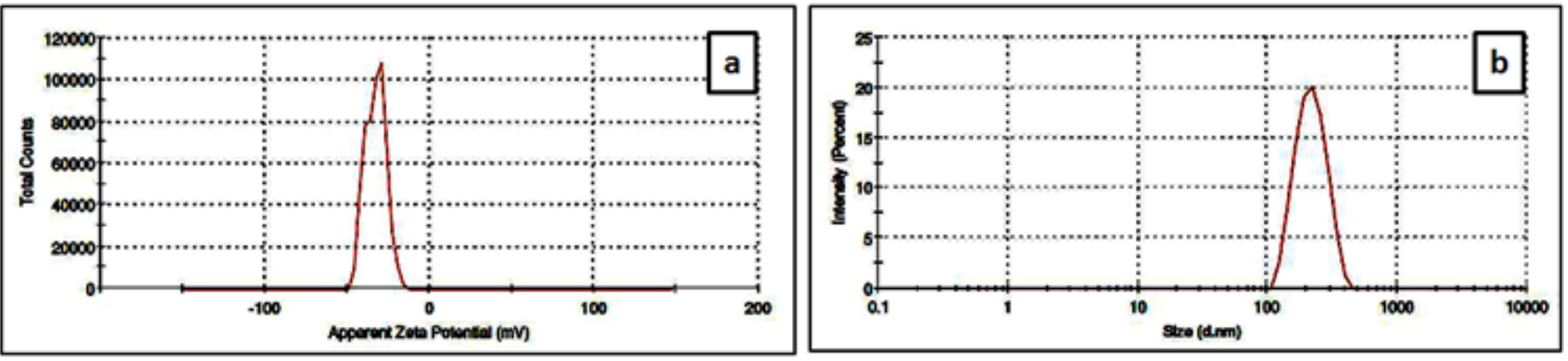

Figure 6

(a) Zeta potential analysis of ZnO NSs and (b) Particle size distribution of ZnO NSs. 

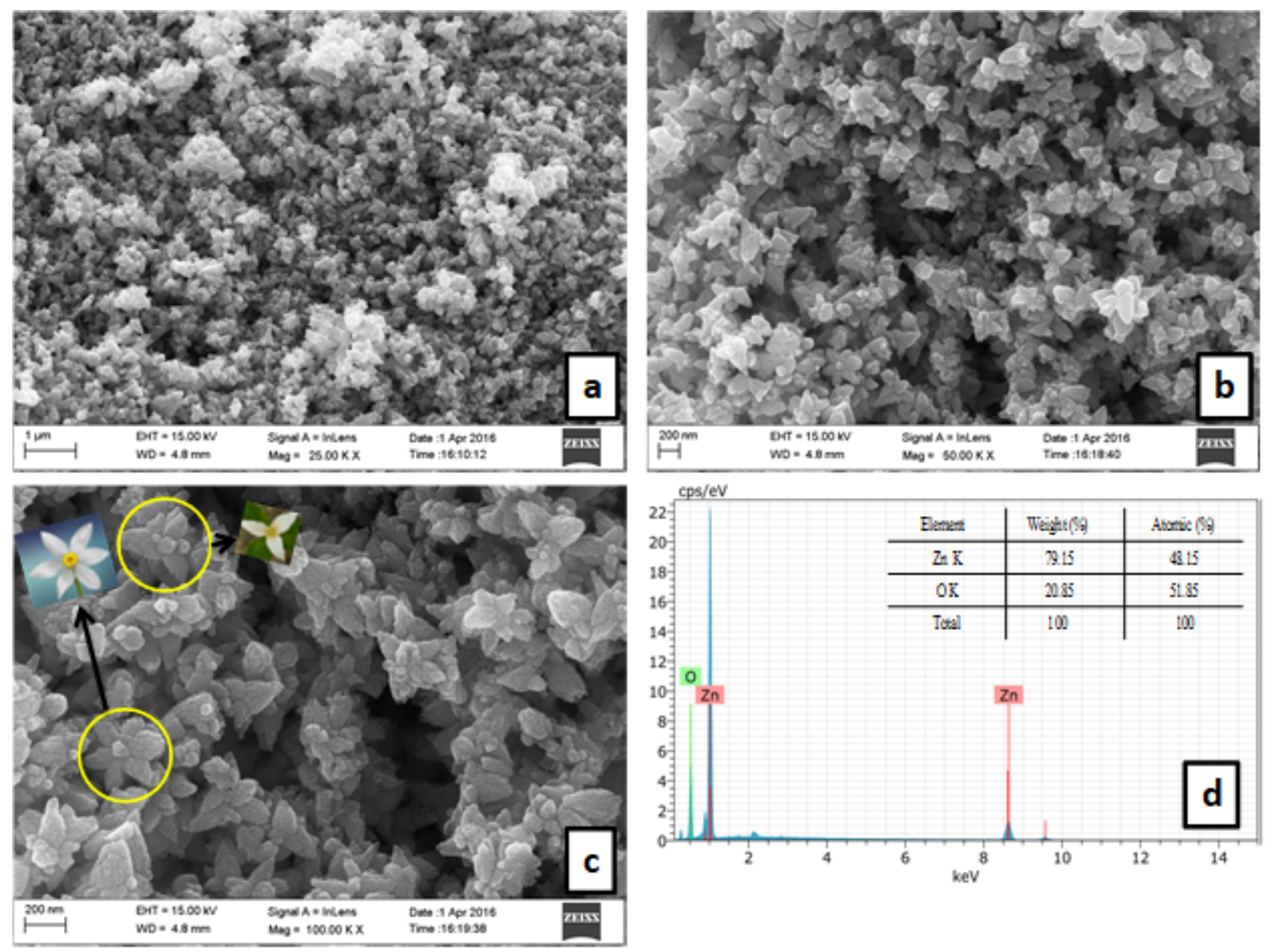

\section{Figure 7}

(a, b \& c) FESEM images of flower like ZnO NSs (under different magnifications) and (d) EDAX spectrum of ZnO NSs. 


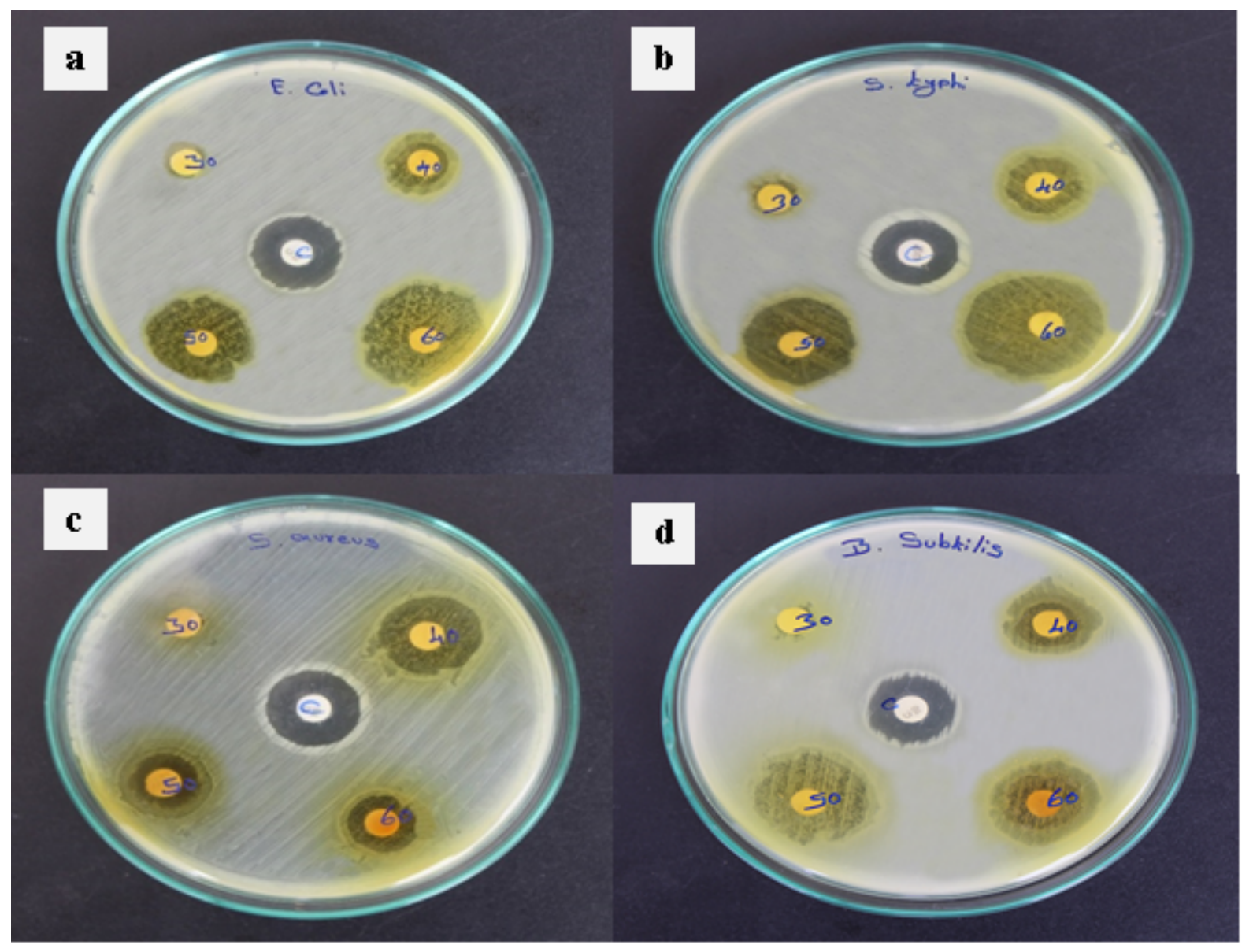

Figure 8

Zone of inhibition ( $\mathrm{mm}$ ) of different human bacterial microorganism impacts using (a) E. coli, (b) S. typhi, (c) S. aureus, and (d) B. subtilis. 


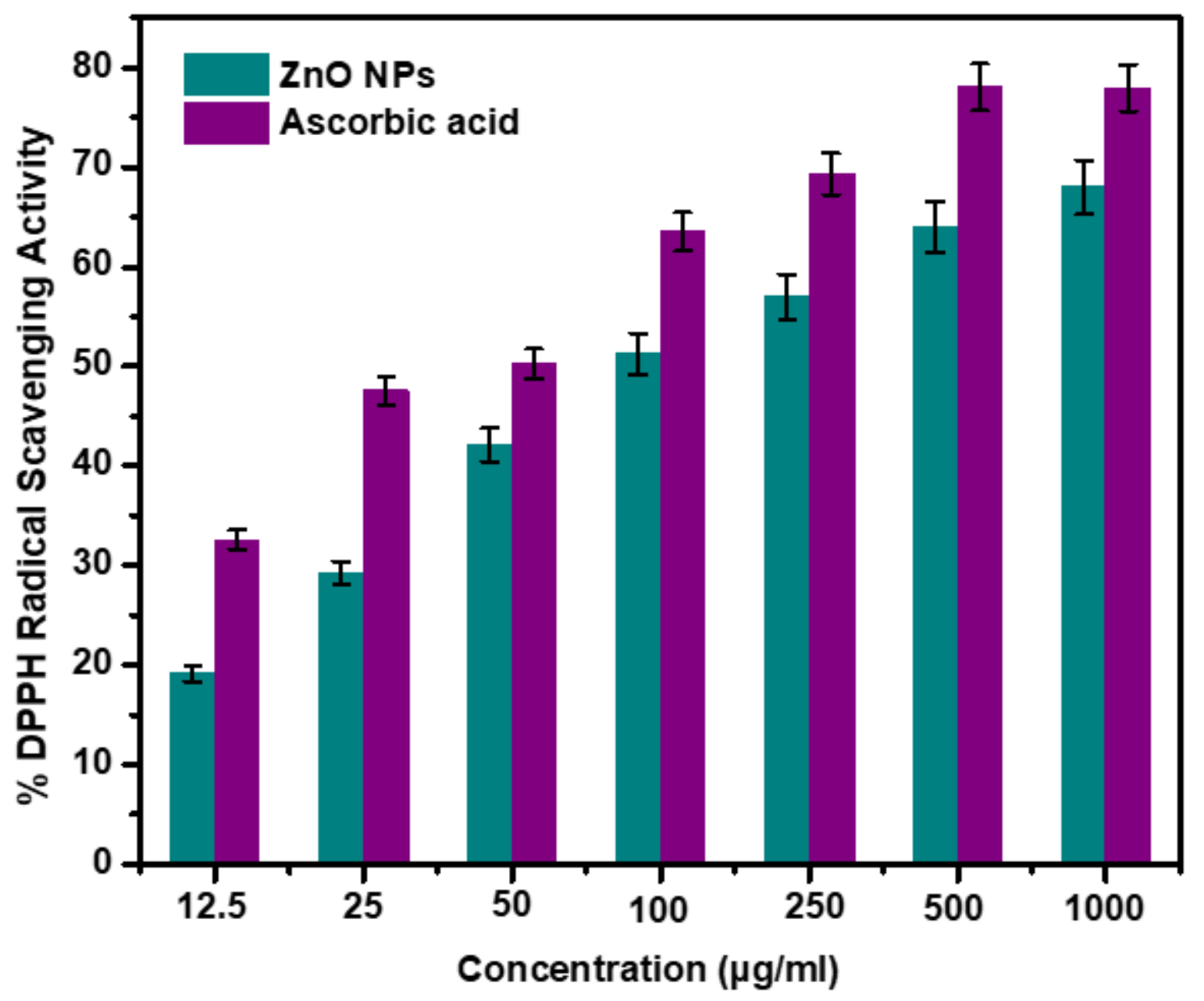

Figure 9

DPPH radical scavenging activity of flower like ZnO NSs using ascorbic acid as a standard 

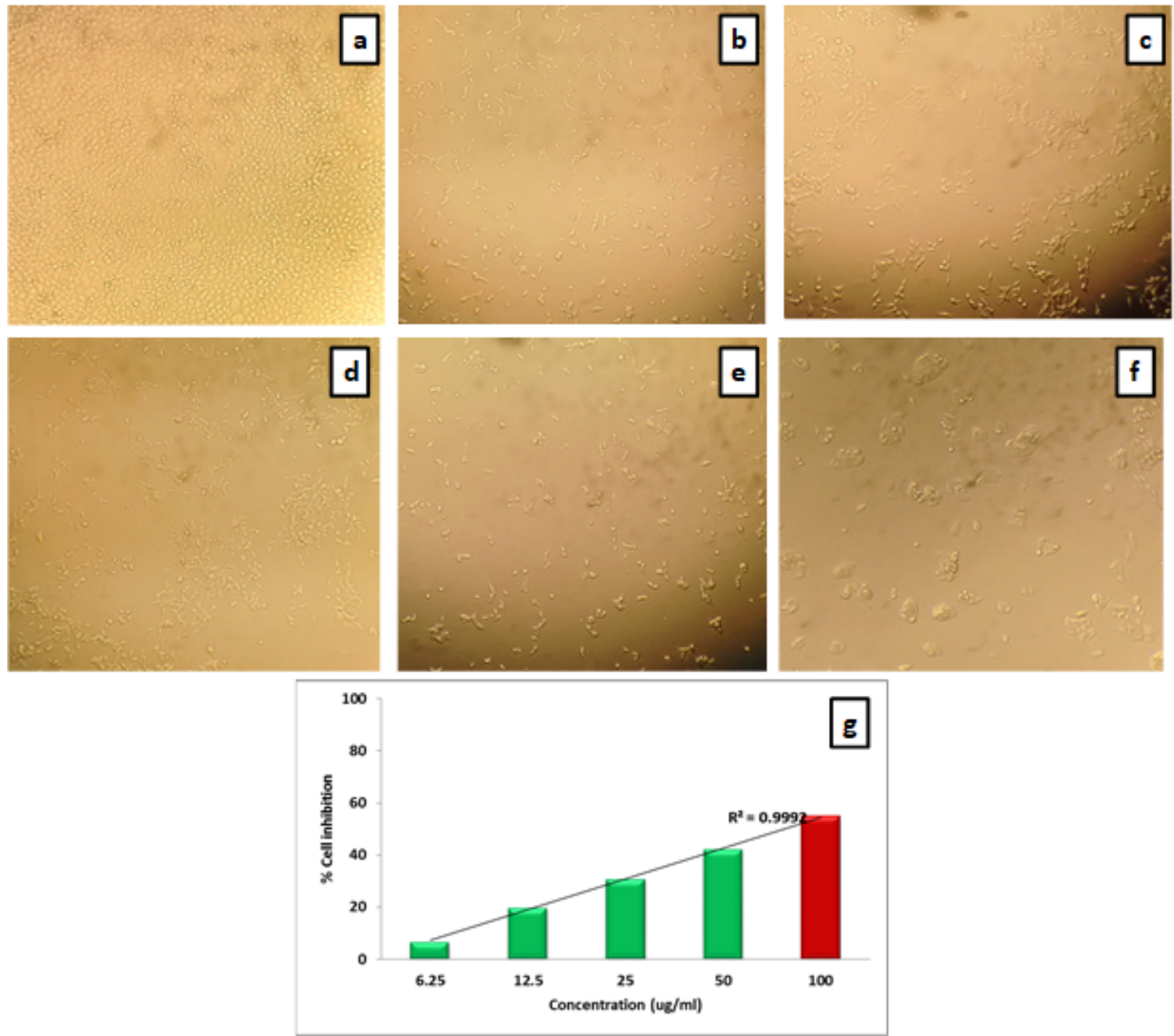

Figure 10

Microscopic cell images of MCF-7 cell line of control (a) and flower like ZnO NSs at various concentrations (b) 6.25 (c) 12.5 (d) 25 (e) 50 (f) $100 \mu \mathrm{g} / \mathrm{ml}$;(g) The percentage of cell viability of control and flower like ZnO NSs by MTT assay at different concentrations $(6.25-100 \mu \mathrm{g} / \mathrm{ml})$. The results are represented as mean $\pm S D(n=3)$ 


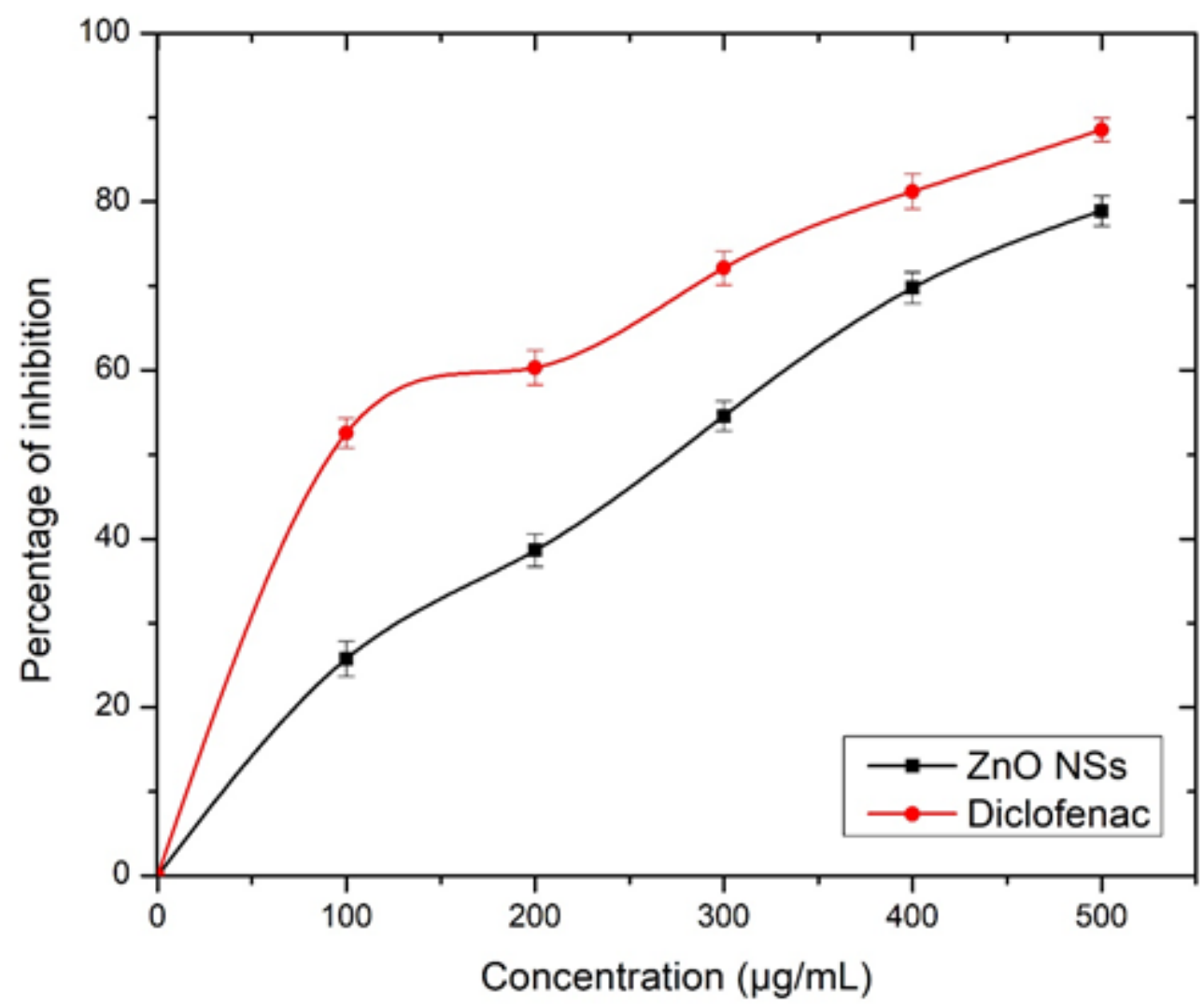

Figure 11

Protein denaturation inhibition activity of flower like ZnO NSs synthesized from Oryza Punctata

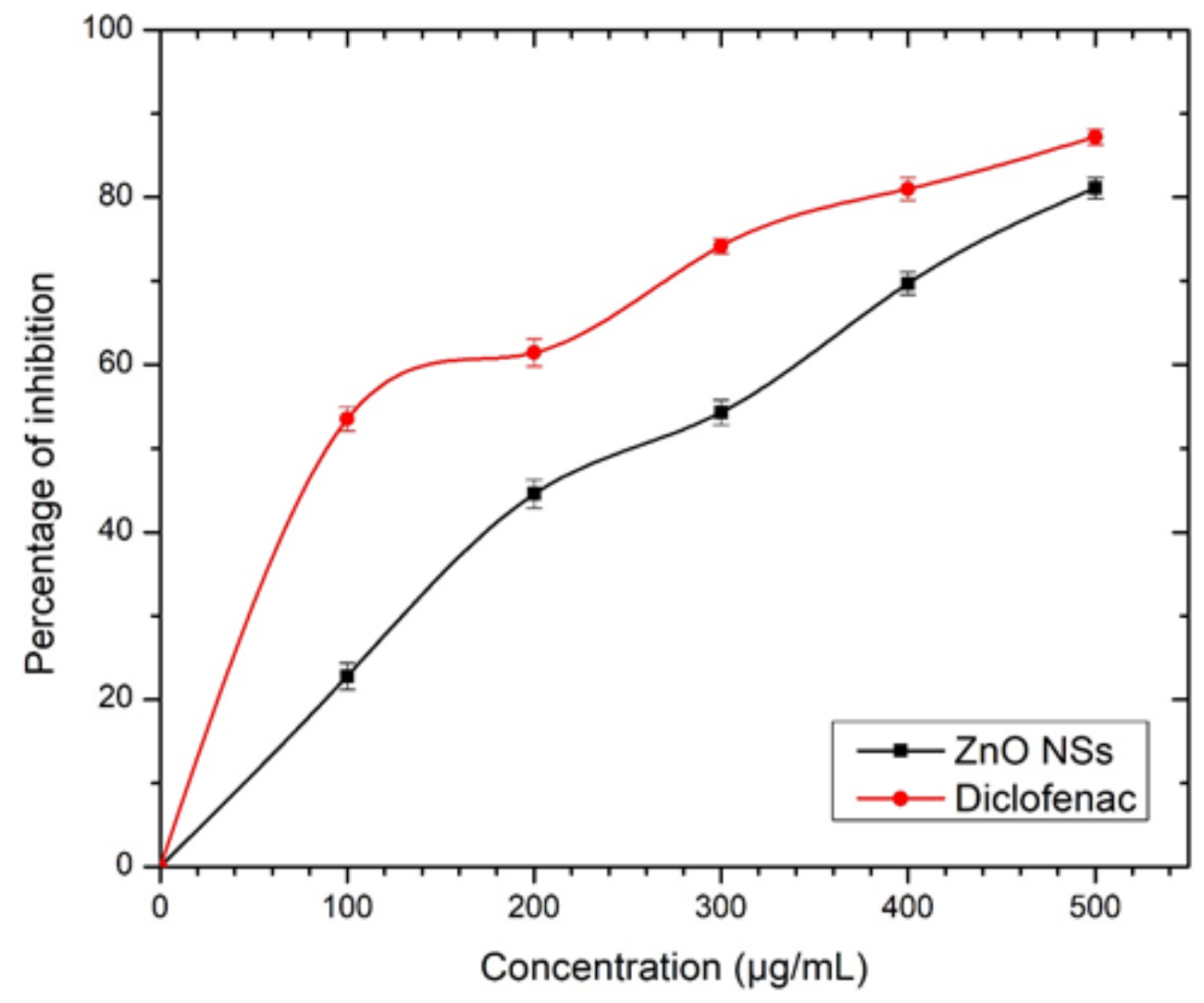

Figure 12 
Membrane stabilization activity of flower like ZnO NSs synthesized from Oryza Punctata 